\title{
Discharge considerations for adult asthmatic patients treated in emergency departments
}

\author{
ANTON F GRUNFELD MD FRCPC, J MARK FITZGERALD MB FRCPC \\ Department of Emergency Medicine and University of British Columbia Respiratory Clinic, \\ Vancouver Hospital and Health Sciences Centre, Vancouver, British Columbia
}

\begin{abstract}
AF Grunfeld, JM FitzGerald. Discharge considerations for adult asthmatic patients treated in emergency departments. Can Respir J 1996;3(5):322-327.
\end{abstract}

OBJECTIVE: To review the medical literature on outcome of treatment of acute asthma in the emergency department and issue recommendations regarding patient admission or discharge.

DATA SOURCES: A MEDLINE search was done for articles in the English language on acute asthma and treatment in the emergency department for the years 1975 to 1993 . In addition, references in pertinent review articles were reviewed.

STUDY SELECTION: Studies addressing treatment of acute asthma in emergency departments were selected by consensus.

DATA SYNTHESIS: Three major areas have been shown to affect outcome and the decision to admit or discharge a patient following treatment in the emergency department: first, the severity of the attack and the response to therapy; second, historical risk factors; and third, care following discharge from the emergency department. This paper reviews the literature on outcome of acute asthma attacks and issues recommendations regarding objective airflow measurements and co-existing risk factors to be assessed before discharging patients. The role of anti-inflammatory therapy in emergency department treatment and in postdischarge treatment of these patients is also reviewed.
CONCLUSION: Evaluation for discharge following treatment of acute asthma should integrate objective measures of airflow obstruction with historical high risk factors. The use of systemic corticosteroids in the emergency department and following discharge, with careful follow-up, may help control the attack and reduce relapse of asthma.

Key Words: Acute asthma, Discharge criteria, Outcome, Therapy

\section{Questions relatives au congé des adultes asth- matiques traités aux services des urgences}

OBJECTIF : Revoir la littérature médicale sur les résultats du traitement de l'asthme aigu au service des urgences et émettre des recommandations quant à l'hospitalisation ou la nonhospitalisation des patients.

SOURCES DES DONNÉES : Dans MEDLINE, on a recherché les articles de langue anglaise portant sur l'asthme aigu et son traitement au service des urgences, de 1975 à 1993. De plus, on a passé en revue les références dans les articles de synthèse pertinents. SÉLECTION DES ÉTUDES : Les études traitant du traitement de l'asthme aigu aux services des urgences ont été sélectionnées par consensus.

SYNTHÈSE DES DONNÉES : On a démontré que trois facteurs principaux affectaient les résultats de la décision visant à hospitaliser ou à donner congé à un patient suite à un traitement au service des urgences. En premier, la gravité de la crise d'asthme et la réponse au traitement; en second, les antécédents de facteurs de

voir page suivante 
risque, et en troisième, les soins que le patient recevra à sa sortie du service des urgences. Le présent article passe en revue la littérature sur l'aboutissement des crises d'asthme aiguës et émet des recommandations à propos de la mesure objective du débit aérien et des facteurs de risque concomitants qui doivent être évalués avant de donner congé aux patients. Le rôle d'une thérapie antiinflammatoire administrée à ces patients au service des urgences, et suite à leur congé, est aussi examiné.
CONCLUSION : La décision de donner congé aux patients après le traitement d'une crise d'asthme aiguë doit tenir compte des mesures objectives de l'obstruction bronchique et des antécédents des facteurs de risque. L'utilisation de corticostéroïdes par voie générale au service des urgences, et suite au congé, accompagnée d'un suivi rigoureux, peut favoriser la maîtrise des crises d'asthme et réduire la fréquence des rechutes.
A lthough the great majority of patients treated in emergency departments (ED) with acute asthma recover and are safely discharged home, significant morbidity and mortality are well-recognized (1-3). The important outcomes to be prevented are death or a near fatal event, and relapse with a further episode of acute asthma. Because most asthma deaths occur in the community and those deaths that occur in the ED are usually in patients who arrive moribund (2), this article focuses on the ED evaluation of patients in whom a decision regarding admission or discharge needs to be made. In addition, it will review the important role of antiinflammatory therapy in the follow-up care of these patients.

\section{DISCHARGE CONSIDERATIONS}

Because of the complexity of medical and nonmedical factors associated with the outcome of an asthmatic attack (4), our ability to predict and alter it is imperfect. The three major areas that have been shown to affect outcome and thus require evaluation before discharging the patient are as follows:

- the severity of the attack and response to therapy;

- historical high risk factors;

- care following discharge.

\section{SEVERITY OF THE ATTACK AND RESPONSE TO THERAPY}

The assessment of the severity of an acute asthma attack is based both on clinical examination and on the objective evaluation of airflow obstruction. Several physical signs have been recognized as being associated with lifethreatening asthma, such as tachycardia, tachypnea, use of accessory muscles, pulsus paradoxus, diaphoresis and an inability to complete sentences in one breath. More ominous signs include a silent chest, cyanosis, bradycardia and decreased levels of consciousness. It must be noted that the ab- sence of these signs cannot be interpreted as signifying that the attack is not life-threatening. In addition, studies in both adults and children failed to show a good correlation between the physical findings and physiological measurements in the assessment of acute airway obstruction (5-7), underlining the need for using objective airflow measurements in addition to the clinical examination.

Attempts have been made to construct and validate severity scores for acute asthma to predict the need for hospitalization and safety in discharging patients. Fischl et al (8) developed an index score based on heart rate over 120 beats/min, respiratory rate more than 30 breaths/min, pulsus paradoxus $18 \mathrm{mmHg}$ or greater, peak expiratory flow rate (PEFR) $120 \mathrm{~L} / \mathrm{min}$, moderate to severe dyspnea, the use of accessory muscles and wheezing. Each of the signs was scored with one point. The authors found that a score of 4 or more was $96 \%$ accurate in predicting the need for hospitalization and $95 \%$ accurate in predicting relapse. However, when this scale was tested prospectively in two other locations, it failed to show any useful predictive value $(4,9)$.

Several authors have correlated the severity of airway obstruction on presentation and at discharge from the ED with the probability that the patient would suffer a relapse. In a prospective study, Kelsen et al (7) found no significant difference in the initial level of airflow obstruction between patients who did and those who did not experience relapse within the next 10 days (mean forced expiratory volume in $1 \mathrm{~s}\left[\mathrm{FEV}_{1}\right]$ was $1.15 \mathrm{~L}$ for the group as a whole, $\left.\mathrm{P}>0.05\right)$. However, patients with significantly lower levels of lung function and a smaller degree of improvement in lung function at the time of discharge were shown to be more likely to suffer a subsequent relapse (Table 1). Patients who showed an $\mathrm{FEV}_{1}$ increase after treatment of $400 \mathrm{~mL}$ had a $67 \%$ relapse rate, while those with an improvement of more than $400 \mathrm{~mL}$ had a relapse rate of only $29 \%$.

Banner and co-workers (10), in a prospective evaluation

TABLE 1

Forced expiratory volume in $1 \mathrm{~s}(\mathrm{~L})$ at presentation and discharge

\begin{tabular}{lcccccc}
\hline & Presentation & Duccessfully & & \multicolumn{2}{c}{ Discharge } \\
Reference & Admitted & Relapsed & $\begin{array}{c}\text { Successfully } \\
\text { discharged }\end{array}$ & Admitted & $\begin{array}{c}\text { Relapsed } \\
\text { discharged }\end{array}$ \\
\hline Kelsen et al (7) & & 1.51 & 1.51 & 1.03 & 1.56 & 1.88 \\
Nowak et al (11) & 0.47 & 0.72 & 0.98 & 1.04 & 1.65 & 1.91 \\
Nowak et al (12) & 0.65 & 0.82 & 1.16 & 1.02 & 1.80 \\
Nowak et al (13) & 0.68 & 0.86 & 1.12 & 2.24 & 2.16 \\
\hline
\end{tabular}


TABLE 2

Percentage predicted values (forced expiratory volume in $1 \mathrm{~s}$ and peak expiratory flow rate) at presentation and discharge

\begin{tabular}{|c|c|c|c|c|c|c|}
\hline \multirow[b]{2}{*}{ Reference } & \multicolumn{3}{|c|}{ Presentation } & \multicolumn{3}{|c|}{ Discharge } \\
\hline & Admitted & Relapsed & $\begin{array}{c}\text { Successfully } \\
\text { discharged }\end{array}$ & Admitted & Relapsed & $\begin{array}{l}\text { Successfully } \\
\text { discharged }\end{array}$ \\
\hline Banner et al (10) & & $<16 \%$ & & & $\leq 42 \%$ & $70 \%$ \\
\hline Nowak et al (12) & $28 \%$ & $28 \%$ & $40 \%$ & $42 \%$ & $55 \%$ & $75 \%$ \\
\hline Nowak et al (12) & $19 \%$ & $25 \%$ & $34 \%$ & $33 \%$ & $49 \%$ & $65 \%$ \\
\hline Nowak et al (13) & $30 \%$ & $29 \%$ & $40 \%$ & $43 \%$ & $52 \%$ & $72 \%$ \\
\hline Nowak et al (13) & $20 \%$ & $25 \%$ & $33 \%$ & $32 \%$ & $50 \%$ & $63 \%$ \\
\hline
\end{tabular}

TABLE 3

Peak expiratory flow rate (L/min) at presentation and discharge

\begin{tabular}{lcccccc}
\hline & Presentation & Successfully & & Discharge \\
References & Admitted & Relapsed & discharged & Admitted & $\begin{array}{c}\text { Successfully } \\
\text { Relapsed }\end{array}$ \\
\hline Fischl et al (8) & 94 & 89 & 157 & 118 & 191 & 299 \\
Nowak et al (12) & 126 & 122 & 179 & 184 & 248 & 336 \\
Nowak et al (13) & 134 & 128 & 176 & 187 & 217 & 323 \\
\hline
\end{tabular}

TABLE 4

\section{Spirometric criteria for deciding to admit or discharge} adult patients with acute asthma

Spirometry to assess the likely need for hospital admission or
discharge should be done on arrival (if the patient tolerates the
procedure) and after bronchodilator therapy
Decision regarding discharge is usually made after $1 \mathrm{~h}$ or more of
therapy
Pretreatment
FEV $V_{1}<1.0 \mathrm{~L}$ or PEFR $<100 \mathrm{~L} / \mathrm{min}$ or $<25 \%$ predicted or best:
patient will usually require admission
Post-treatment
FEV $1<1.6 \mathrm{~L}$ or PEFR $<200 \mathrm{~L} / \mathrm{min}$ or $<40 \%$ predicted or best:
admission is recommended
FEV $11.6-2.1 \mathrm{~L}$ or PEFR 200 to $300 \mathrm{~L} /$ min, or between $40 \%$ and
$60 \%$ predicted or best: discharge may be possible after
considering the risk factors and follow-up care
FEV $1>2.1 \mathrm{~L}$ or PEFR $>300 \mathrm{~L} /$ min or $>60 \%$ predicted or best:
discharge is likely after considering the risk factors and follow-up
care

$\overline{F E V_{1} \text { Forced expiratory volume in } 1 \mathrm{~s} \text {; PEFR Peak expiratory flow }}$ rate

of 67 episodes of acute asthma, found that patients who were successfully discharged had a median peak flow of $70 \%$ predicted. In the seven episodes where the treatment failed, no patients had peak flow greater than $42 \%$ predicted. In addition, patients with initial peak flows of less than $16 \%$ predicted and less than $16 \%$ improvement after an initial injection of adrenaline were admitted or had a relapse (Table 2).

Fischl et al (8), in a prospective evaluation of 205 patients with acute asthma, found that PEFR at presentation was significantly higher in patients who were successfully discharged than in those who were admitted or relapsed (157 $\mathrm{L} / \mathrm{min}$ versus $94 \mathrm{~L} / \mathrm{min}$ and $89 \mathrm{~L} / \mathrm{min}$, respectively). At disposition, PEFRs in successfully discharged patients were significantly better than those in patients who experienced a relapse, which were better than those in admitted patients (299 L/min, versus $191 \mathrm{~L} / \mathrm{min}$, versus $118 \mathrm{~L} / \mathrm{min}$, respectively) (Table 3).

Nowak et al (11), in a prospective evaluation of 85 episodes of acute asthma, also found significant differences in $\mathrm{FEV}_{1}$ among the three groups of patients, both at the time of presentation and following treatment (Table 1). Thirty-five per cent of the patients studied had an initial FEV 1 of $0.6 \mathrm{~L}$ or less and a post-treatment $\mathrm{FEV}_{1}$ of $1.6 \mathrm{~L}$ or less. Ninety per cent of patients either were admitted or had a subsequent relapse.

In two further studies, Nowak et al $(12,13)$ also found significant differences among values of airflow in admitted patients, patients who developed problems following discharge and patients who were discharged without relapse (Tables 1-3). In one of these studies (12), $92 \%$ of patients with a pretreatment PEFR of less than $100 \mathrm{~L} / \mathrm{min}$ and a post-treatment value of less than $300 \mathrm{~L} / \mathrm{min}$ required admission or had an unsuccessful out-patient course. Of patients with a pretreatment PEFR of less than $100 \mathrm{~L} / \mathrm{min}$ and an improvement of less than $60 \mathrm{~L} / \mathrm{min}$ after initial terbutaline, $85 \%$ were admitted or had problems after discharge.

Fanta et al (14), in a prospective evaluation of different therapeutic combinations, found that the rate and magnitude of response in the first hour depended on the severity of airway obstruction at presentation. In this study it was found that patients with an initial $\mathrm{FEV}_{1}$ of less than $30 \%$ predicted and who did not improve to an $\mathrm{FEV}_{1}$ of at least $40 \%$ predicted at the end of 60 mins of intense bronchodilator therapy required prolonged ED treatment and/or hospital admission.

The data in these studies show consistency in correlating spirometric measurements and outcome. This allows for recommendations regarding discharge of asthmatic patients from the ED, as summarized in Table 4. The absolute values 
given are approximations for the 'average adult'. Percentage predicted or previous best are more helpful when available. The pre- and post-treatment $\mathrm{FEV}_{1}$ or PEFR are probably the best guides to therapy.

However, there are two points worth noting: first, corticosteroids were not routinely used as part of the protocol in these studies; and second, the discharge criteria suggested in these studies, based on airflow obstruction, have not been prospectively validated.

Several authors have showed that reliance on $\mathrm{FEV}_{1}$ or PEFR as the only criterion to predict the need for hospitalization or relapse has limitations. Verbeek and Chapman (15) examined Nowak's data and showed that using a proposed PEFR above $300 \mathrm{~L} / \mathrm{min}$ or an $\mathrm{FEV}_{1}$ greater than $2.1 \mathrm{~L}$ would lead to one-third of all recommended admissions being unnecessary. Worthington and Ahuja (16) found that using the combination of $\mathrm{FEV}_{1}$ of at least $0.7 \mathrm{~L}$ at presentation and $\mathrm{FEV}_{1}$ of at least $2.1 \mathrm{~L}$ before discharge had a low positive predictive value $(47 \%)$ for admission or relapse. However, a final $\mathrm{FEV}_{1}$ of greater than $2.4 \mathrm{~L}$ had a high sensitivity $(90 \%)$ and negative predictive value (94\%) when used as a criteria for discharge. Patients who attained this value could be discharged with a high degree of confidence. While indicating a safe discharge, this cut-off value was not useful for deciding admission because of the low specificity of only $41 \%$. In this study, knowledge of the $\mathrm{FEV}_{1}$ did not alter the decision to admit or discharge a patient in $97 \%$ of cases.

In spite of the above limitations, because of the known variations in the ability of patients to estimate the severity of airflow obstruction (17-20) the measurements are important, not only in gauging objectively the response to therapy, but also in integrating these levels into decisions regarding disposition, as outlined above.

\section{HISTORICAL HIGH RISK FACTORS}

Studies of asthma deaths have identified historical factors that increase the risk of patients dying of their disease. These include a recent hospital admission, a recent visit to the ED, poor medical management and poor compliance (21-28).

In a retrospective case control study of death from asthma, Rea et al (29) confirmed the significance of these risk factors. In addition, they showed that psychological problems were more common in cases than in controls. These included recent unemployment, recent bereavement, depression, personality disorders and alcohol abuse. They concluded that the best way to identify asthma patients at risk of death is to identify those who have had a recent hospital admission and, in particular, those who have ever had a life-threatening attack requiring mechanical ventilation.

The existence of two groups of patients who are considered at risk of dying from asthma was noted at a recent consensus meeting on asthma mortality (30). The groups are:

- patients with a history of near fatal episodes, requiring resuscitation, regardless of the underlying severity of disease or presence of any other risk factors

\section{TABLE 5}

Historical high risk factors associated with asthma relapse

Previous near fatal episode

Sudden precipitous attacks

Allergic or anaphylactic triggers

Recent emergency department visit

Frequent hospitalizations

Dependence on systemic steroids or recent use

Recent attack of prolonged duration

Poor compliance or knowledge of asthma

Returning to the same environmental triggers

- patients with underlying severe disease, judged by chronic severe symptoms, systemic steroid requirement, frequent regular use of bronchodilators, frequent ED visits or hospitalizations. Patients in this group may also have one or more of the following problems: recent discharge from the hospital for severe asthma, poor self-care or noncompliance with medications, depression or severe emotional disturbance, significant other psychological factors, or shortcomings in education and supervision.

The potential role of indiscriminate use of beta-agonists as a risk factor for fatal asthma has received attention recently. A number of case control studies from New Zealand have suggested that the use of fenoterol may be associated with an increased risk of death from asthma $(31,32)$. More recently, Spitzer et al (33) matched 129 cases who had fatal or near fatal asthma and compared them with 655 controls from the Saskatchewan Health Insurance database. The use of both fenoterol and albuterol was associated with increased risk of death (OR 2.6 per canister per month, CI 1.7 to 3.9) and of death or near death from asthma considered together (OR 1.9 per canister per month). The adverse effect of regular use of beta-agonist was also shown by Sears et al (34) in a crossover study that compared on-demand versus regular use of fenoterol. The regular use of fenoterol was associated with less optimal asthma control than its use on demand.

Molfino et al (35) examined the characteristics of 10 patients who arrived at hospital in respiratory arrest or in whom it developed within 20 mins of arrival at the ED. These patients were similar to those described in the literature with a high risk of death from asthma, including a long history of asthma in young- to middle-aged patients, previous lifethreatening attacks or hospitalization, delay in medical aid and sudden onset of a rapidly progressive attack. Extreme hypercapnia and acidosis were found before mechanical ventilation was begun, but no patient developed serious cardiac arrhythmias during resuscitation. They suggest that undertreatment, as shown by severe asphyxia, rather than overtreatment with potential cardiotoxicity, may be a major factor in the increased number of deaths from asthma.

Kallenbach et al (36) studied 81 patients with acute severe asthma in whom mechanical ventilation was required. In this group of patients they found no evidence to support the con- 
TABLE 6

\section{Recommendations for follow-up care}

Majority of patients require systemic corticosteroids in the emergency department and following discharge

Patients need to be educated in the use of their medication and recognition and treatment of relapse

Follow-up by the family doctor or a specialist, especially in high risk cases, is required

cept of cardiotoxicity related to bronchodilators contributing significantly to mortality from asthma. On the contrary, there appeared to have been serious undertreatment in many cases, particularly as regards corticosteroids. The investigators identified a group of patients with 'hyperacute' asthma in whom the duration of the attack from onset to mechanical ventilation was less than $3 \mathrm{~h}$. This group was associated with an increased risk of near fatal episodes $(\mathrm{P}<0.03)$, and hyperacute attacks were uniformly near fatal.

The data in these studies show consistency and allow for recommendations regarding the consideration of historical risk factors before discharge of asthmatic patients from the ED. Patients with the characteristics listed in Table 5 are at risk of relapse. However, it is worth noting that these high risk criteria have not been validated in prospective studies.

\section{FOLLOW-UP CARE}

In recent years the pivotal role that airway inflammation plays in the pathogenesis of asthma has been recognized (37). Jeffrey et al (37), in an ultrastructural study of biopsies taken from the airways of patients with asthma and compared with control subjects, showed the presence of inflammatory changes in the patients with asthma that were not found in the controls. They in particular found an increase in lymphocytes in the airway and postulated that these cells play a prominent role in the inflammatory process. It follows that patients presenting to the ED have a significant amount of airway mucosal inflammation and edema. These airway changes have been the basis for the many recommendations to use antiinflammatory therapy, usually in the form of systemic corticosteroids (38). Despite this rationale patients continue to be discharged from the ED without such therapy (39), leading to unacceptably high rates of relapse as well as ongoing poor symptom control.

A recent meta-analysis (40), as well as a preliminary report of our own (41), critically reviewed the current literature and made specific recommendations as to dosage and route of administration of corticosteroids in acute asthma. Rowe and Oxman (40) reviewed over 700 articles and found 30 relevant randomized controlled trials. They found that early use of corticosteroids for exacerbations reduced hospital admissions for adults (OR $0.47,95 \%$ CI 0.27 to 0.79 ) and children (OR 0.06 to 0.42 ). In the out-patient setting they also found that corticosteroids prevented relapses in patients with acute exacerbations (OR $0.15,95 \%$ CI 0.05 to 0.44 ). The majority of patients who come to the ED with acute asthma have disease of such severity that systemic corticosteroids are re- quired. Largely based on one study the dose of corticosteroids given has usually been $125 \mathrm{mg}$ of methylprednisolone intravenously (42). However, a number of studies have shown that oral prednisone will suffice, even in subjects requiring hospital admission $(43,44)$. Rowe also looked at the effect size of oral versus intravenous corticosteroids and found no difference in the groups treated with either route.

Traditionally a dose of prednisone $40 \mathrm{mg}$ has been recommended for subjects discharged from the ED (45). Where this dose is used, and in the presence of the ongoing use of inhaled anti-inflammatory steroids, routine tapering of corticosteroids at the end of a 10-day course of systemic medication is not required (46). O'Driscoll et al (46) evaluated 35 patients admitted to hospital with an acute exacerbation of asthma, randomized them to a 10-day course of prednisolone $40 \mathrm{mg}$ daily and then randomized them to placebo or a traditional tapering dose and found no difference between the two groups. The importance of maintenance anti-inflammatory inhaled corticosteroids can be gauged from the fact that, although there was a treatment effect at the end of 10 days in the study of Chapman et al (45), there was no such difference at 21 days, showing that short term benefit of systemic corticosteroids is rapidly lost in the absence of appropriate ongoing care.

Although the use of a doubling dose of inhaled corticosteroids has been recommended in a number of asthma guidelines (47), there are no published data supporting this recommendation in preventing the evolution of deteriorating asthma into a full-blown acute attack. Although intuitively it makes sense, the dosing and duration of such therapy needs to be validated in a prospective study.

Patients are usually referred to family physicians for follow-up within the following week to monitor response to therapy. There is evidence, however, that facilitated referral to a specialist leads to improvement in ongoing asthma care (48) and likely leads to a better transition from acute care to appropriate ongoing control of the underlying asthma. The integration of a program of asthma education and these therapeutic interventions will likely lead to better results $(49,50)$. These studies support the recommendations listed in Table 6 .

\section{CONCLUSIONS}

Patients presenting to the ED should have airflow obstruction evaluated objectively. These measurements should be integrated with historical features outlined above in coming to a decision on admission or discharge. The use of systemic corticosteroids and follow-up with topical inhaled corticosteroids will ensure good initial and ongoing control of asthma and prevent many admissions to hospital, reduce relapse rate and, over time, lead to lower asthma morbidity and likely mortality.

ACKNOWLEDGEMENTS: This paper was prepared in conjunction with the development of Guidelines for Emergency Management of Adult Asthma by the Asthma Work Group of the Canadian Association of Emergency Physicians. The authors also thank Drs Naser Awadh and Kendall Ho for their review of the manuscript. 


\section{REFERENCES}

1. Sears MR, Beaglehole R. Asthma morbidity and mortality: New Zealand. J Allergy Clin Immunol 1987;80:383-8.

2. Benatar SR. Fatal asthma. N Engl J Med 1986;314:423-9.

3. Jackson R, Sears MR, Beaglehole R, Rea HH. International trends in asthma mortality: 1970 to 1985 . Chest 1988;94:914-8.

4. Centor RM, Yarborough B, Wood JP. Inability to predict relapse of acute asthma. N Engl J Med 1984;310:577-80.

5. McFadden ER, Kiser R, DeGroot WJ. Acute bronchial asthma, relations between clinical and physiologic manifestations. N Engl $\mathrm{J}$ Med 1973;288:221-5.

6. Kerem F, Canny G, Tibshirani R, et al. Clinical-physiologic correlations in acute asthma in childhood. Pediatrics 1991;87:481-6.

7. Kelsen SG, Kelsen DP, Fleegler BF, et al. Emergency room assessment and treatment of patients with acute asthma: adequacy of the conventional approach. Am J Med 1978;64:622-8.

8. Fischl MA, Pitcheaik A, Gardner LB. An index predicting relapse and need for hospitalisation in patients with acute bronchial asthma. $\mathrm{N}$ Engl J Med 1981;305:783-9.

9. Rose CC, Murphy JG, Schwartz JS. Performance of an index predicting the response of patients with acute bronchial asthma to intensive emergency department treatment. N Engl J Med 1984;310:573-6.

10. Banner AS, Shah RS, Addington WW. Rapid prediction of the need for hospitalisation in acute bronchial asthma. JAMA 1976;235:1337-8.

11. Nowak RM, Gordon KR, Wroblewski SA, et al. Spirometric evaluation of acute bronchial asthma. J Am Coll Emerg Physicians 1979;8:9-12.

12. Nowak RM, Pensler MI, Sarkar DD, et al. Comparison of peak expiratory flow and FEV 1 admission criteria for acute bronchial asthma. Ann Emerg Med 1982;11:64-9.

13. Nowak RM, Tomlanovich MC, Sarkar DD, et al. Arterial blood gases and pulmonary function testing in acute bronchial asthma: predicting patient outcomes. JAMA 1983;249:2043-6.

14. Fanta CH, Rosing TH, McFadden ER. Emergency room treatment of asthma, relationship among therapeutic combinations, severity of obstruction and time course of response. Am J Med 1982;72:416-22.

15. Verbeek PR, Chapman KR. Asthma: whom to send home, when to hospitalise. J Respir Dis 1986;7:15-31.

16. Worthington JR, Ahuja J. The value of pulmonary function tests in the management of acute asthma. Can Med Assoc J 1989;140:153-6.

17. Rubinfeld AR, Pain MC. Perception of asthma. Lancet 1976;i:882-4.

18. Burdon JG, Juniper EF, Killian KJ. The perception of breathlessness in asthma. Am Rev Respir Dis 1982;126:825-8.

19. Boulet LP, Deschesnes F, Gignac F, Turlotte H. Near fatal asthma: Clinical and physiologic features, perception of bronchoconstriction and psychologic profile. J Allergy Clin Immunol 1991;88:838-46.

20. McFadden ER. Clinical physiologic correlates in asthma. J Allergy Clin Immunol 1986;77:1-5.

21. Fatal asthma. Lancet 1979;ii:337-8. (Edit)

22. Johnson AJ, Nunn AJ, Somner AR, et al. Circumstances of death from asthma. BMJ 1984;288:1870-2.

23. Cochrane GM, Clark TJH. A survey of asthma mortality in patients between ages 35 and 64 in the Greater London hospitals in 1971. Thorax 1975;30:300-5.

24. Macdonald JB, Seaton A, Williams DA. Asthma death in Cardiff in 1963-74: 90 deaths outside hospital. BMJ 1976;i:1493-5.

25. Macdonald JB, Macdonald ET, Seaton A, Williams DA. Asthma deaths in Cardiff 1963-74: 53 deaths in hospital. BMJ 1976;i:721-3.

26. Omerod LP, Stableforth DE. Asthma mortality in Birmingham 1975-7: 53 deaths. BMJ 1980;280:687-90.

27. Hetzel MR, Clark TJH, Branthwaite MA. Asthma: analysis of sudden death and ventilatory arrests in hospital. BMJ 1977;i:808-11.

28. Fraser PM, Speizer FE, Waters SDM, et al. The circumstances preceding death from asthma in young people in 1968 to 1969 . $\mathrm{Br} \mathrm{J}$ Dis Chest 1971;65:71-84.

29. Rea HH, Scrago R, Jackson R, et al. A case control study of death from asthma. Thorax 1986;41:833.

30. Workshop on the identification of the fatally prone patient with asthma, summary of workshop discussion. Proceedings of the Asthma Mortality Task Force. J Allergy Clin Immunol 1987;80:455-7.

31. Pearce N, Grainger J, Atkinson M, et al. Case control study of prescribed fenoterol and death from asthma in New Zealand 1977-1981. Thorax 1990;45:170-5.

32. Grainger J, Weedman K, Pearce N, et al. Prescribed fenotorol and death from asthma in New Zealand 1981-1987: a further case control study. Thorax 1991;46:105-11

33. Spitzer WO, Suissa S, Ernest $P$, et al. The use of $\beta$-agonists and the risk of death and near death from asthma. N Engl J Med 1992;326:501-6.

34. Sears MR, Taylor DR, Print CG, et al. Regular inhaled beta agonist treatment in bronchial asthma. Lancet 1990;336:1391-6.

35. Molfino NA, Nannini LJ, Martell AN, Slutsky AS. Respiratory arrest in near-fatal asthma. N Engl J Med 1991;324:285-8.

36. Kallenbach JM, Frankel AH, Lapinsky SE, et al. Determinants of near fatality in acute severe asthma. Am J Med 1993;95:265-72.

37. Jeffrey PK, Wardlaw AJ, Nelson FC, Collins JV, Kay AB. Bronchial biopsies in asthma: an ultrastructural, quantitative study and correlation with hyperreactivity. Am Rev Respir Dis 1989;140:1745-53.

38. FitzGerald JM, Hargreave FE. The assessment and management of acute life threatening asthma. Chest 1989;140:520-6.

39. FitzGerald JM, Hargreave FE. Emergency department management of acute asthma and a prospective evaluation of outcome. Can Med Assoc J 1990;142:591-5.

40. Rowe BH, Keller JL, Oxman AD. Effectivenes of steroid therapy in acute exacerbation of asthma: a meta-analysis. Am J Emerg Med 1992;10:301-10.

41. FitzGerald JM, Kearon MC. Corticosteroids in acute asthma: optimal dose and route of administration. Results of a meta-analysis. Am Rev Respir Dis 1990;143(Suppl):A624.

42. Littenberg B, Gluck E. A controlled trial of methylprednisolone in the emergency department for acute asthma. N Engl J Med 1986;314:150-2.

43. Harrison BD, Stokes TC, Hart GJ, Vaughan DA, Ali NJ, Robinson AA. Need for intravenous hydrocortisone in addition to oral prednisolone in patients admitted to hospital with severe asthma without ventilatory failure. Lancet 1986;i:181-4.

44. Ratto D, Alfaro C, Sipsey J, Glovsky MM, Sharma OP. Are intravenous corticisteroids required in status asthmaticus? JAMA 1988;260:527-9.

45. Chapman KR, Verbeek PR, White JG, Rebuck AS. Effect of a short course of prednisone in the prevention of early relapse after the emergency room treatment of acute asthma. N Engl J Med 1991;324:788-94.

46. O'Driscoll BR, Kalra S, Wilson M, et al. Double blind trial of steroid tapering in acute asthma. Lancet 1993;341:324-7.

47. Hargreave FE, Newhouse NY, Dolovich J. Guidelines for reducing asthma morbidity and mortality. J Allergy Clin Immunol 1990;85:1098-111.

48. Zeiger RS, Heller S, Mellon MH, et al. Facilitated referral to asthma specialist reduces relapses in asthma emergency room visits. J Allergy Clin Immunol 1991;87:1160-8.

49. FitzGerald JM, Swan D, Turner M. The role of asthma educator. Can Med Assoc J 1992;147:855-6. (Edit)

50. Mayo PH, Richman J, Harris HW. Results of a program to reduce admission for adult asthma. Ann Intern Med 1990;112:864-71. 


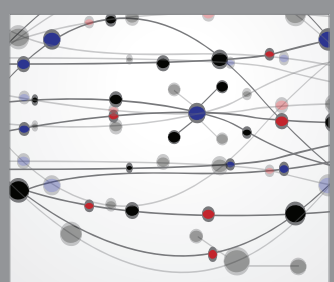

The Scientific World Journal
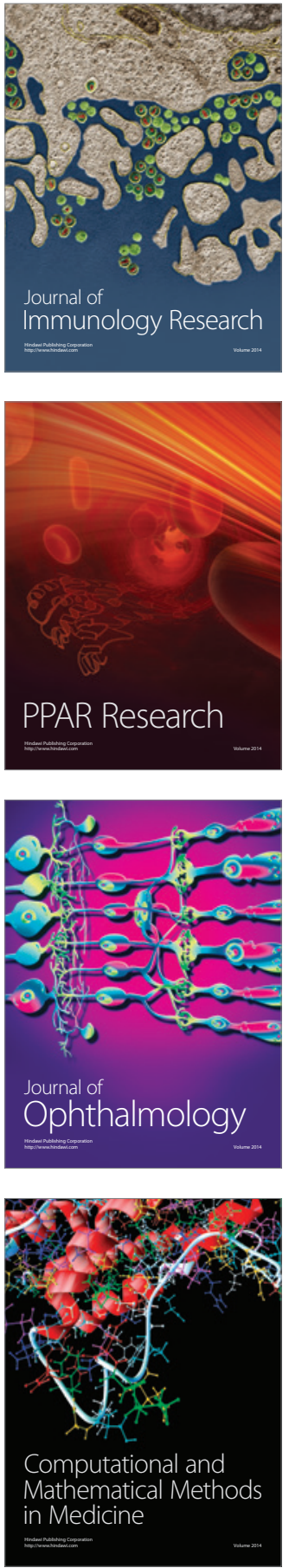

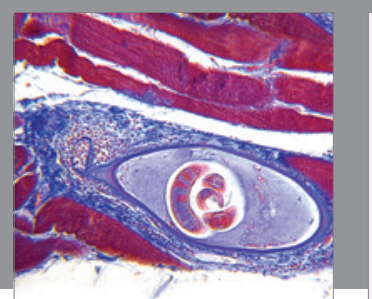

Gastroenterology Research and Practice

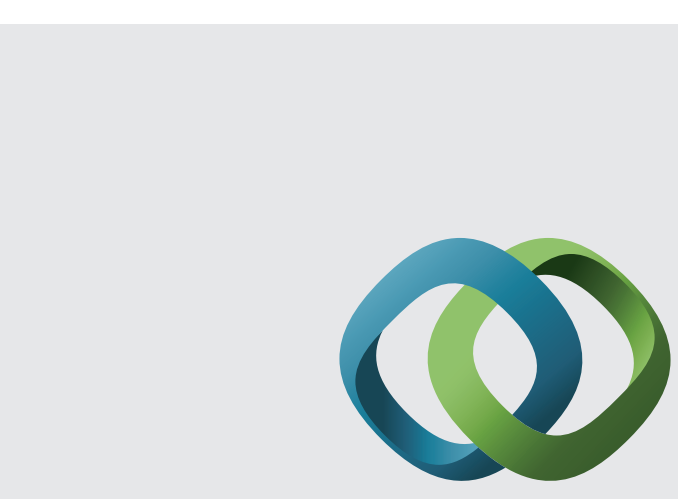

\section{Hindawi}

Submit your manuscripts at

http://www.hindawi.com
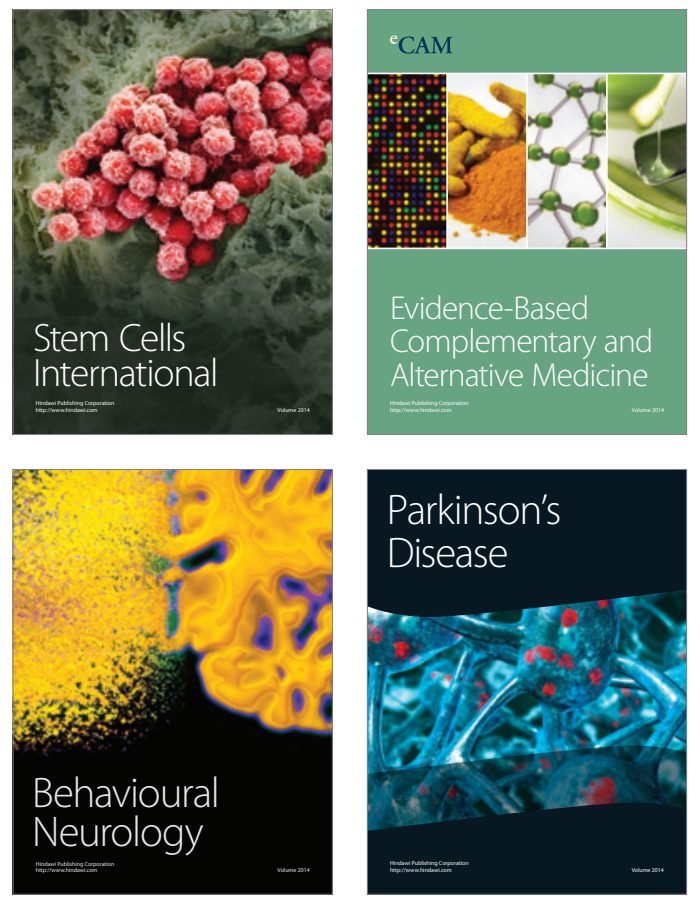
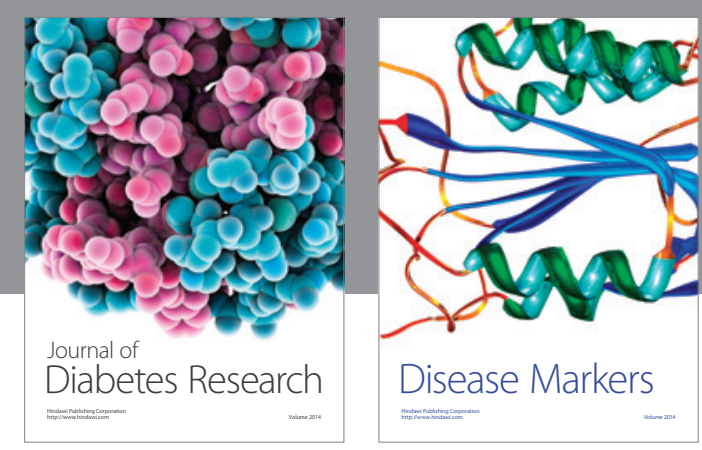

Disease Markers
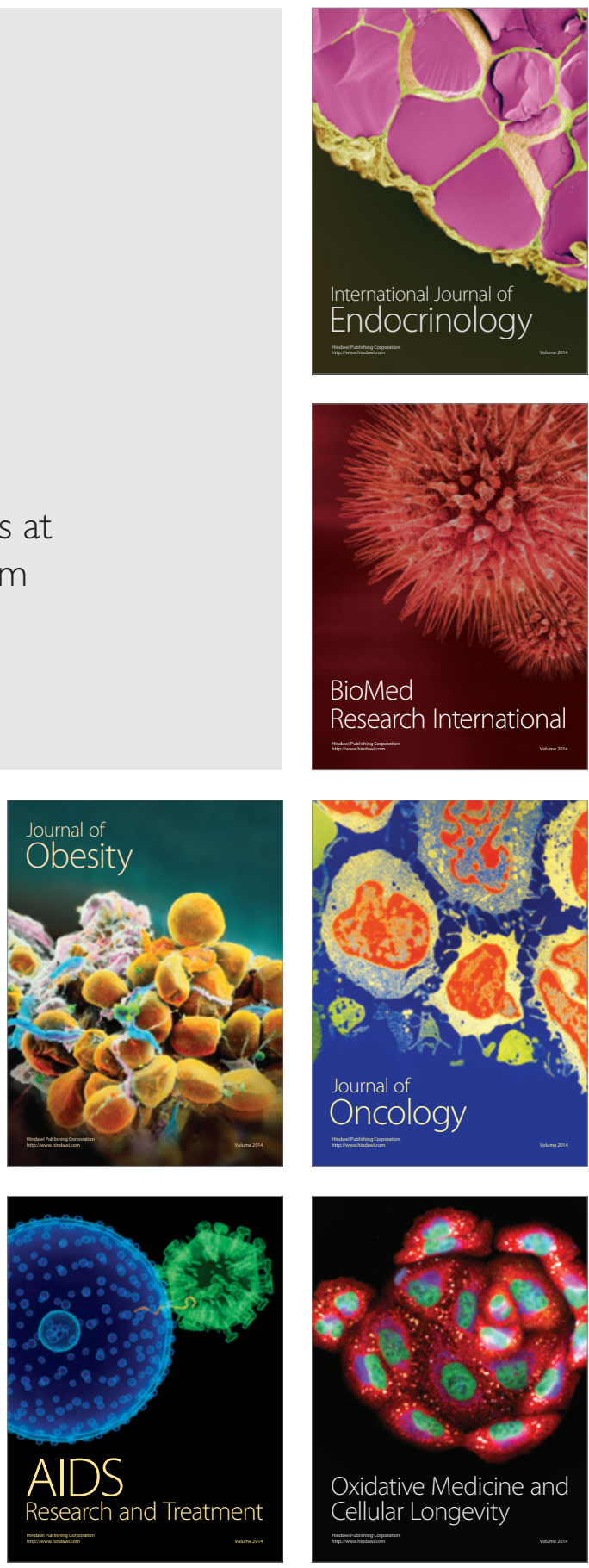